\title{
Prevalence of bacterial vaginosis among pregnant women attending antenatal care in Tikur Anbessa University Hospital, Addis Ababa, Ethiopia
}

\author{
Zemenu Mengistie $^{1 *}$, Yimtubezinash Woldeamanuel ${ }^{2}$, Daniel Asrat $^{2}$ and Addis Adera ${ }^{3}$
}

\begin{abstract}
Background: Bacterial vaginosis is one of the most common genital tract infections among reproductive age group. The prevalence of bacterial vaginosis varies from country to country even in the same country it varies among populations of interest. Different social and sexual factors can contribute to the development of bacterial vaginosis. The aim of this study was to determine the prevalence of bacterial vaginosis and to identify the possible risk factors associated among pregnant women attending antenatal care in Tikur Anbessa University Hospital, Addis Ababa, Ethiopia.

Methods: Randomly selected 57 symptomatic and 195 asymptomatic pregnant women aged between 18 and 40 years visiting obstetric and gynecological clinic from November 2011 to April 2012 screenedusing Gram stain Nugent scoring system. Statistical analysis like univariate analysis to calculate frequencies and proportions, bivariate analysis to see association of selected exposure variables with the outcome variable, and multivariate analysis to check the association of possible factors with bacterial vaginosis by adjusting potential confounding factors was calculated using SPSS (Version 16.0).

Results: The prevalence of bacterial vaginosis is $19.4 \%$ using Gram stain Nugent scoring system. In addition, prevalence of bacterial vaginosis is $31.6 \%$ and $15.9 \%$ among symptomatic and asymptomatic pregnant women respectively. A high percentage of bacterial vaginosis positive pregnant women were asymptomatic (63.3\%). 36.7\% bacterial vaginosis positive pregnant women reported abnormal vaginal discharge with or without unpleasant smell. Multiple lifetime sexual partner (OR: 8.6; $95 \%$ Cl: $2.5,29)$ and previous history of spontaneous abortion (OR: 5.9; $95 \%$ Cl: 1.5, 23) had remained significantly associated with prevalence of bacterial vaginosis.
\end{abstract}

Conclusion: The prevalence of bacterial vaginosis is higher among asymptomatic pregnant women and associated with the factors previous history of multiple lifetime sexual partner and spontaneous abortion.

Keywords: Bacterial vaginosis, Pregnancy, Prevalence

\section{Background}

Bacterial vaginosis (BV) is a shift in the vaginal ecosystem characterized by an overgrowth of anaerobes, and a decrease in Lactobacillus resulting in degradation of the natural flora that helps keep the vaginal tissue healthy [1]. It is a very common infection in women, and there is a lack of understanding regarding the triggers and factors for the onset and resolution of it [2].

\footnotetext{
* Correspondence: zemenumengistie@yahoo.com

'Department of Medical Microbiology, Mizan Tepi University, P.O. Box 260, Mizan, Ethiopia

Full list of author information is available at the end of the article
}

Bacterial vaginosis is an important gynecologic problem of childbearing age group of women worldwide. The presence of bacterial vaginosis has consistently been shown to be a risk factor for adverse obstetric outcomes such as preterm labor and delivery, preterm premature rupture of membranes, spontaneous abortion, and postpartum infections such as endometritis and caesarean section wound infections [3-5]. It also increases the risk of HIV acquisition by approximately 60 percent; because BV increases HIV genital shedding with in discharge and results in increased concentration of HIV in genital secretions, which in turn facilitates both vertical and sexual HIV transmission [6-8]. 
The prevalence rates of bacterial vaginosis among pregnant women vary from 6.4 percent to 38 percent $[9,10]$. It has been found that the lower the socioeconomic status of the population, the higher the incidences of bacterial vaginosis, which may indicate health and hygiene factors, play an even bigger role than anticipated [11]. The methods of diagnosis used for diagnosis ofBV can also have an effect on the variation of BV prevalence. The gold standard for diagnosis of BV is microscopic criteria proposed by Nugent [12]. The clinical criteria by Amsel do not require laboratory facilities, specialized staff and there is no delay in reporting. However, it is difficult to evaluate all of these criteria for diagnosis of BV in busy practice; and it requires the ability of the gynecologist to analyze wet mount microscopy.

Although many studies of $\mathrm{BV}$ have been done in different country,currently we know of no published studies that have been conducted in Ethiopia to describe the prevalence of BV among pregnant women. In order to avoid the above aforementioned pregnancy complications during $\mathrm{BV}$ infection screening and treating of pregnant women is crucial. Therefore, the present study was carried out to determine the prevalence ofbacterial vaginosis and associated factors among pregnant women visiting antenatal care (ANC).

\section{Methods}

Fifty seven symptomatic and 195 asymptomatic pregnant women aging 18 to 40 years included in the study by simple randomsampling technique. These were outpatient clients visiting obstetrical and gynecological clinical for antenatal care services of a tertiary level hospital in Addis Ababa from November 2011 to April 2012. The nurse interviewers performed a comprehensive review of the prenatal and ultrasound record; and completed the standardized baseline questionnaire containing information regarding maternal age, gravidity, previous pregnancy outcomes, demographic, vaginal hygiene and contraceptive use. Information on the presence and type of vaginal discharge, history of sexual transmitted infection or genital tract infection, history of $\mathrm{BV}$, vaginal douching practices and sexual practices also collected using questioner. The questionnaires filled in a confidential location within the office by a female nurse interviewer. Vaginal bleeding and antibiotic treatment in the preceding two weeks used as exclusion criteria.

After physical and obstetrical examination by the attending physician or obstetrician vaginal sample was collected from lateral wall of the vagina and then smeared on a slide and transported to microbiology department for Gram staining for Nugent scoring. This is a standardized 0-10 point scoring system for evaluation of Gram stained vaginal smears based on three morphotypes: large gram positive rods (lactobacilli), small gram negative/variable rods (G. vaginalisand anaerobic rods) and curved gram variable rod (Mobiluncusspecies). A score of $0-3$ is considered normal, 4-6 intermediate, 7-10 positive for BV [12].

Data entered using EPI data then exported to SPSS version 16.0 for analysis. Statistical analysis like univariate analysis to calculate frequencies and proportions, bivariate analysis to see association of selected exposure variables with the outcome variable, and multivariate analysis to cheek the association of possible factors with bacterial vaginosis for adjusting potential confounding factors calculated using SPSS.

The Research and Ethical Review Committee (REC) of Addis Ababa University approved the research project proposal. Written informed consent obtained from willing pregnant women and symptomatic pregnant women having BV positive treated by $500 \mathrm{mg}$ oral metronidazole twice daily for seven days.

\section{Results}

The mean age of the study participant was $27.6( \pm 4.7)$ years and all are resident in urban. In addition nearly all $241(95.6 \%)$ of the study participants were married and 201(79.8\%) had only one lifetime sexual partner. Among 161(63.9\%) multigravida pregnant women, 24 (14.9\%) of pregnant women had previous history of spontaneous abortion. None of the study participants had vaginal douching practice in the preceding month.

The Gram stain result of 183(72.6\%) study participant classified as normal, 20 (7.9\%) participant diagnosed as an intermitted while the remaining 49 (19.4\%) were positive for bacterial vaginosis by Nugent scoring system. As shown in Table 1, the prevalence of bacterial vaginosis among symptomatic pregnant was $18(31.6 \%)$ but among asymptomatic the prevalence of $\mathrm{BV}$ was $31(15.9 \%)$.

Table 1 Prevalence of bacterial vaginosis based on Nugent scoring system among pregnant women attending ANC in Tikur Anbessa university hospital (November 2011 - April 2012)

\begin{tabular}{|c|c|c|c|c|c|}
\hline & \multicolumn{2}{|c|}{ Microbiological diagnosis } & \multirow[b]{2}{*}{ Total no. (\%) } & \multirow[t]{2}{*}{ Odd ratio } & \multirow[t]{2}{*}{$p$-value } \\
\hline & Positive no. (\%) & Negative no. (\%) & & & \\
\hline Symptomatic & $18(36.7)$ & 39 (19.2) & $57(22.6)$ & 2.44 & $<0.05(0.032)$ \\
\hline Asymptomatic & $31(63.3)$ & $164(80.8)$ & $195(77.4)$ & 1.00 & \\
\hline Total & $49(19.4)$ & $203(80.6)$ & $252(100)$ & & \\
\hline
\end{tabular}


Table 2 Univariate \& Multivariate analysis of factors association with bacterial vaginosis among pregnant women attending ANC in Tikur Anbessa Hospital (November 2011 - April 2012)

\begin{tabular}{clll}
\hline Variables & BV positive & BV negative & Univariate; COR \\
\hline $\begin{array}{clll}\text { Age (year) } \\
\leq 20\end{array}$ & $3(17.6)$ & $14(82.4)$ & $1.09(0.27,4.33)$ \\
$21-29$ & $33(21.2)$ & $123(78.8)$ & $1.36(0.67,2.77)$ \\
$30+$ & $13(16.5)$ & $66(83.5)$ & 1.00 \\
Religion & & & \\
Orthodox & $40(22.2)$ & $140(77.8)$ & 1.00 \\
Muslim & $7(13.7)$ & $44(86.3)$ & $0.56(0.23,1.33)$ \\
Protestant & $2(9.5)$ & $19(90.5)$ & $0.37(0,08,1.65)$
\end{tabular}

Education

$\begin{array}{llll}<\text { Grade } 12 \text { complete } & 25(23.1) & 83(76.9) & 1.51(0.81,2.82) \\ \geq \text { Grade } 12 \text { complete } & 24(16.7) & 120(83.3) & 1.00\end{array}$

Occupation

$\begin{array}{llll}\text { Employed } & 19(18.1) & 86(81.9) & 1.00 \\ \text { House wife } & 24(20.3) & 94(79.7) & 1.16(0.59,2.26) \\ \text { Others } & 6(20.7) & 23(79.3) & 1.18(0.42,3.3)\end{array}$

Income (ETB)

$$
\begin{aligned}
& \leq 500 \\
& 501-1500 \\
& >1500
\end{aligned}
$$

Number of LTSP

$$
\begin{aligned}
& \text { One } \\
& \text { Two and above }
\end{aligned}
$$

Gestational age

$$
\begin{aligned}
& \text { 1st trimester } \\
& \text { 2nd trimester }
\end{aligned}
$$$$
\text { 3rd trimester }
$$

Number of pregnancy

$$
\text { Primigravidia }
$$

\section{History of abortion}

Yes-spontaneous

Yes-induce

No

29(31.5)

63(68.5)

$60(82.2)$

13(17.8)

80(92.0)

181(90)

22(43.1)

13(36.1)

23(63.9)

19(20)

$76(80)$

17(14)

104(86)

17(18.7)

$74(81.3)$

129(80.1)

12(50)

12(50)

4(66.7)

113(86.3)

18(14)

46(18.8)

199(81.2)

4(57.1)

Vaginal bathing

Daily
Less than daily

Showering frequency

Daily

Less than daily

16(57.1)

12(42.9)

191(85.3)

1.00

Previous BV/GTI

$\begin{array}{llll}\text { Yes } & 3(15) & 17(85) & 1.4(0.39,4.99) \\ \text { No } & 46(19.8) & 186(80.2) & 1.00\end{array}$

$$
\begin{aligned}
& * 5.26(2.16,12.8) \\
& 2.48(0.93,6.58) \\
& 1.00
\end{aligned}
$$

1.00

*11.9(5.8, 24.5)

$8.6(2.5,29)$

$0.01 *$

*3.46(1.48, 8.1)

$1.9(0.4,8.6)$

0.40

$1.53(0.75,3.14)$

1.00

1.00

$1.08(0.56,2.08)$

*6.28(2.45, 16.11)

$5.9(1.3,23)$

$0.012^{*}$

$3.14(0.54,18.41)$

1.00

*7.72(3.35, 17.78)

p-value

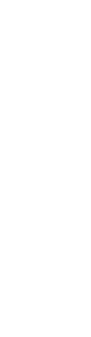

0.17

$0.31(0.07,1.43)$

1.00

2.7(0.6, 12)

0.19 
Table 2 Univariate \& Multivariate analysis of factors association with bacterial vaginosis among pregnant women attending ANC in Tikur Anbessa Hospital (November 2011 - April 2012) (Continued)

\author{
Yeast infection

$\begin{array}{lll}\text { Yes } & 9(32.1) & \text { 19(67.9) }\end{array}$ \\ $\begin{array}{lll}\text { No } & \text { 40(17.9) } \quad 184(82.1) \quad 1.00\end{array}$ \\ COR - Crude Odd Ratio; AOR - Adjusted Odd Ratio LTSP - Life Time Sexual Partner; ETB- Ethiopian Birr GTI- Genital Tract Infection; *statistically significant.
}

Majority (63.3\%) of Bacterial vaginosis diagnosed pregnant women were asymptomatic.

More vaginal symptoms were reported from BV negative pregnant women than BV positive pregnant women but abnormal discharge with unpleasant smell was reported more frequently by BV positive women. Out of unusual vaginal discharge complained women only 27 (47.4\%) had non-Candida like discharge and non-Candida like discharge is significantly associated with BV.

In the Bivariate analysis (Table 2) personal monthly income $\leq 500 \mathrm{ETB}$, multiple sexual partners history, first trimester gestational age and previous history of spontaneous abortion, daily showering were associated with bacterial vaginosis $(\mathrm{P}<0.05)$. However, after we had adjusted for confounders in multivariate analyses (Table 2), more than one lifetime sexual partners and previous history of spontaneous abortion remained independently associated with increased likelihood of BV positive. Some factors that lacked independent associations with BV during pregnancy remained important confounders and were therefore retained in the final model.

\section{Discussion}

The overall prevalence of bacterial vaginosis by Gram stains Nugent scoring criteria in this study was $19.4 \%$, which was comparable with studies done in India (20.5\%) and in Denmark (17\%) [13,14]. The current study showed lower prevalence of bacterial vaginosis than reports from different sub-Saharan countries like Kenya (37\%), Botswana (38\%), Zimbabwe (32.5\%) using the same methods of diagnosis $[10,15,16]$. The lower prevalence of BV in our study may be due to that absence of vaginal douching among study population. Besides these, the lower prevalence of BV in this study can be also explained as most of the women were in third trimester gestational age since as gestational age increase the prevalence of BV decrease. In contrast to the present study, lower prevalence of bacterial vaginosis was reported in Burkina Faso (6.4\%), India (8.6\%), Sweden (9.3\%), Boston (11\%) and Washington (12\%) [9,17-20]. This may be due to environmental, behavioral, socioeconomic status and stressor differences in the geographical variation.

Bacterial vaginosis is mostly present without sign and symptoms. The most common clinical sign and symptoms of BV is thin white or gray homogenous vaginal discharge with or without unpleasant smell. The smell of the discharge mostly noticed after sexual intercourse $[3,21,22]$. In the current study, we found that $63.3 \%$ of participants who were diagnosed positive for BV by gram stain had no symptom for BV. This result is consistent with other studies done in different countries $[10,23,24]$. In this study the result also showed that the Vaginal discharge complains by women has less value as diagnostic algorithm because approximately one-third (31.6\%) of BV positive participants were only reported abnormal discharge when asked. The finding are consistent with other study which report that only very few women reported vaginal symptom when asked [15]. Comparing with a women having Candida like discharge, pregnant women with non-Candida like abnormal discharge had a greater chance (OR: 4.6; 95\% CI: 1.4, 15.7; $\mathrm{p}=0.014$ ) to be positive for bacterial vaginosis.

In addition, our result also found that the presence of abnormal vaginal discharge $(\mathrm{p}=0.01)$ and unpleasant smell $(\mathrm{p}=0.005)$ were reported vaginal symptoms associated with bacterial vaginosis. In general abnormal vaginal discharge is not accurate sensitive indicator of $\mathrm{BV}$ status in this study which confirms the suggestions by other studies [10,25]; but symptomatic pregnant women have more than a twofold increased chance to be positive for bacterial vaginosis than asymptomatic.

With consideration to the above findings, it can be concluded that bacterial vaginosis has a varying degree of prevalence rate among people of different communities which might be due to certain factors such as hygiene behaviors and sociodemographic characteristics. Therefore, it is important to try to establish a correlation between BV and factors affecting its prevalence. Because our sample population was exclusively urban living and nearly all women were married, had no previous history of preterm and stillbirth and had daily vaginal bathing, we could not effectively examine the association of BV with these risk factors. As well, we were unable to compare the frequency of bacterial vaginosis among religious denominations due to lack of comparability in the number of participants. In our study, there was a significant correlation between number of lifetime sexual partner and prevalence of BV. Multiple lifetime sexual partners were more likely risk factors for bacterial vaginosis. This is consistent with other researcher findings [3,26-28]; while others finding showed no significant correlation in this regard [29]. In addition to this factor, consistent 
with other study done among pregnant women in Burkina Faso [9]; we found that previous spontaneous abortion is independently associated as a risk factor of bacterial vaginosis infection.

\section{Conclusion}

The overall prevalence of bacterial vaginosis among pregnant women is $19.4 \%$. The prevalence of BV among symptomatic pregnant women was $31.6 \%$ while among asymptomatic pregnant women, it was $15.9 \%$ and BV infection is mostly asymptomatic. Since common asymptomatic nature of BV infection, screening of women having an experience of multiple lifetime sexual partner and previous history of spontaneous abortion is vital for good pregnancy outcome.

\section{Competing interests}

The authors declare that they have no competing interests.

\section{Authors' contributions}

ZM have made substantial contributions to beginning and design, collection of data, analysis and interpretation of data and in drafting the manuscript and correcting the comment given by the advisors. YW involved in revising the research paper and the manuscript critically for important intellectual content and approval of the final version to be published and participated in its design and coordination. DA participated in the approval and funding process, participated in the design of the study participated in its design and coordination and helped to draft the manuscript. AA had a greater contribution in reviewing the manuscript English and topography. All authors read and approved the final manuscript.

\section{Acknowledgements}

We are thankful to all our departmental technical staff for their excellent technical support. We are grateful to all the participant pregnant women for their kind cooperation and Addis Ababa University and Mizan Tepi University for financial support.

\section{Author details}

'Department of Medical Microbiology, Mizan Tepi University, P.O. Box 260, Mizan, Ethiopia. ${ }^{2}$ Department of Medical Microbiology, Immunology and Parasitology, Addis Ababa University, P.O. Box 9086, Addis Ababa, Ethiopia. ${ }^{3}$ Department of Nursing, Woldia University, P.o.Box 400, Woldia, North Wollo, Ethiopia.

Received: 17 December 2013 Accepted: 16 October 2014

Published: 20 November 2014

\section{References}

1. Joesoef MR, Schmid G: Bacterial vaginosis. Clin Evid 2005, 13:1968-1978.

2. Gellar M, Nelson A: Diagnosis and treatment of recurrent and persistent vaginitis. Womens Health Gynecol 2004, 4:137-146.

3. CDC: Bacterial vaginosis: CDC: bacterial vaginosis. Factsheet 2008, http://www.cdc.gov/std/BV) (Accessed: 29/09/2011.

4. Mullick S, Watson-Jones D, Beksinska M, Mabey D: Sexually transmitted infections in pregnancy: prevalence, impact on pregnancy outcomes, and approach to treatment in developing countries. Sex Transm Infect 2005, 81:294-302.

5. Nelson DB, Macones G: Bacterial vaginosis in pregnancy: current findings and future directions. Epidemiol Rev 2002, 24:102-108.

6. Atashili J, Poole C, Ndumbe PM, Adimora AA, Smith JS: Bacterial vaginosis and HIV acquisition: a meta-analysis of published studies. AIDS 2008, 22:1493-1501.

7. Msuya SE, Uriyo J, Hussain A, Mbizvo EM, Jeansson S, Sam NE, StrayPedersen B: Prevalence of sexually transmitted infections among pregnant women with known HIV status in northern Tanzania. Reprod Health 2009, 6:4.

8. Sha BE, Zariffard MR, Wang QJ, Chen HY, Bremer J, Cohen MH, Spear GT: Female genital-tract HIV load correlates inversely with Lactobacillus species but positively with bacterial vaginosis and Mycoplasma hominis. $J$ Infect Dis 2005, 191:25-32.
9. Kirakoya-Samadoulougou F, Nagot N, Defer MC, Yaro S, Meda N, Robert A: Bacterial vaginosis among pregnant women in Burkina Faso. Sex Transm Dis 2008, 35:985-989.

10. Romoren M, Velauthapillai M, Rahman M, Sundby J, Klouman E, Hjortdahl P: Trichomoniasis and bacterial vaginosis in pregnancy: inadequately managed with the syndromic approach. Bull World Health Organ 2007, 85:297-304.

11. Allsworth JE, Peipert JF: Prevalence of bacterial vaginosis; 2001-2004 National Health and Nutrition Examination Survey data. Obstet Gynacol 2007, 109:114-120.

12. Nugent RP, Krohn MA, Hillier SL: Reliability of diagnosing bacterial vaginosis is improved by standardized method of gram stain interpretation. J Clin Microbiol 1991, 29:297-301.

13. Lata I, Pradeep Y, Sujata, Jain A: Estimation of the incidence of bacterial vaginosis and other vaginal infections and its consequences on Maternal/Fetal outcome in pregnant women attending an antenatal clinic in a Tertiary Care Hospital in North India. Indian J Community Med 2010, 35:285-289.

14. Vogel I, Thorsen P, Jeune B, Jacobsson B, Ebbesen N, Arpi M, Bremmelgaard A, Moller BR: Acquisition and elimination of bacterial vaginosis during pregnancy: Danish population-based study. Infect Dis Obstet Gynecol 2006, 2006:94646.

15. Marx G, John-Stewart G, Bosire R, Wamalwa D, Otieno P, Farquhar C: Diagnosis of sexually transmitted infections and bacterial vaginosis among HIV 1 infected pregnant women in Nairobi. Int J STD AIDS 2010, 21:549-552.

16. Kurewa NE, Mapingure MP, Munjoma MW, Chirenje MZ, Rusakaniko S, StrayPedersen B: The burden and risk factors of sexually transmitted infections and reproductive tract infections among pregnant women in Zimbabwe. BMC Infect Dis 2010, 10:127.

17. Dadhwal V, Hariprasad R, Mitta S, Kapi A: Prevalence of bacterial vaginosis in pregnant women and predictive value of clinical diagnosis. Arch Gynecol Obstet 2010, 281:101-104.

18. Larsson PG, Fahraeus L, Carlsson B, Jakobsson T, Forsum U: Predisposing factors for bacterial vaginosis, treatment efficacy and pregnancy outcome among term deliveries; results from a preterm delivery study. BMC Womens Health 2007, 7:20.

19. Delaney ML, Onderdonk AB: Nugent score related to vaginal culture in pregnant women. Obstet Gynacol 2001, 98:79-84.

20. Krohn MA, Hillier SL, Eschenbach DA: Comparison of methods for diagnosing bacterial vaginosis among pregnant women. J Clin Microbiol 1989, 27:1266-1271.

21. BASHH: National Guideline for the Management of Bacterial Vaginosis. Clinical Effectiveness Group, British Association for Sexual Health and HIV. 2006, www.bashh.org (Accessed: 29/09/2011).

22. Eschenbach DA, Hillier S, Critchlow C, Stevens C, DeRoven T, Holmes KK: Diagnosis and clinical manifestation of bacterial vaginosis. Am J Obstet Gynecol 1988, 158:819.

23. Amsel R, Totten PA, Spiegel CA, Chen KC, Eschenbach D, Holmes KK: Nonspecific vaginitis: diagnostic criteria and microbial and epidemiologic associations. Am J Med 1983, 74:14-22.

24. Ayenalem $S$, Yusuf $L$, Ashenafi M: Lactic acid bacterial vaginosis among outpatients in Addis Ababa. Ethiop J Health Dev 2010, 24:198-204.

25. Nelson DB, Bellamy S, Odibo A, Nachamkin I, Ness RB, Allen-Taylor L: Vaginal symptoms and bacterial vaginosis (BV): how useful is selfreport? Development of a screening tool for predicting BV status. Epidemiol Infect 2007, 135:1369-1375.

26. Bailey JV, Farquhar C, Owen C: Bacterial vaginosis in lesbians and bisexual women. Sex Transm Dis 2004, 31:691-694.

27. Brotman RM, Klebanoff MA, Nansel TR, Andrews WW, Schwebke JR, Zhang J, Yu KF, Zenilman JM, Scharfstein DO: A longitudinal study of vaginal douching and bacterial vaginosis a marginal structural modeling analysis. Am J Epidemiol 2008, 168:188-196.

28. Smart $S$, Singal A, Mindel A: Social and sexual risk factors for bacterial vaginosis. Sex Transm Infect 2004, 80:58-62.

29. Trabert B, Misra DP: Risk factors for bacterial vaginosis during pregnancy among African American women. Am J Obstet Gynecol 2007, 197:477. e1-.8.

doi:10.1186/1756-0500-7-822

Cite this article as: Mengistie et al:: Prevalence of bacterial vaginosis among pregnant women attending antenatal care in Tikur Anbessa University Hospital, Addis Ababa, Ethiopia. BMC Research Notes 2014 7:822. 